\title{
Getting the Green Light: Experiences of Icelandic Mothers Struggling with Breastfeeding
}

\author{
by Sunna Símonardóttir
}

University of Iceland

Sociological Research Online, 21 (4), 1

<http://www.socresonline.org.uk/21/4/1.html>

DOI: $10.5153 /$ sro.4149

Received: 3 Jul 2016 I Accepted: 6 Nov 2016 I Published: 30 Nov 2016

\begin{abstract}
The World Health Organization recommends exclusive breastfeeding for the first six months of life, with continued breastfeeding up to two years of age or beyond. This policy has been adopted by the Nordic countries, including Iceland, where there has been an upward trend towards higher breastfeeding rates and duration. The high breastfeeding rates in Iceland indicate that the idea that all women should breastfeed is culturally very strong. Exclusive breastfeeding is constructed as a pillar of successful bonding and absolutely paramount when it comes to promoting the close primary relationship between mother and child. Previous research on breastfeeding from a socio-cultural point of view remains very much rooted in an Anglo-American context and has mostly been conducted in countries where breastfeeding rates remain relatively low and the cultural context of breastfeeding similar. This paper addresses that particular knowledge gap by making visible the identity work that Icelandic mothers perform in order to be able to construct themselves as "good" responsible mothers and how dominant biomedical discourses on infant feeding and 'good mothering' discursively position women as powerless and unable to make decisions on breastfeeding cessation. The reaction that they experience from their immediate surroundings indicates that their 'failures' in breastfeeding can rarely be constructed as anything other than a personal shortcoming. Whilst the surveillance that they come to expect from other mothers and the general public results in them having to account for their 'lack' of breastfeeding in order to avert the hostile gaze of others.
\end{abstract}

Keywords: Breastfeeding, Motherhood, Parenting Culture, Scientific Discourses, the Body

\section{Introduction}

1.1 Breastfeeding has proved to be an interesting, albeit understudied topic of research for sociologists and feminists interested in motherhood and women's reproductive experiences. This inattention has in turn 'allowed public debates to be dominated by medical practitioners, maternalistic breastfeeding advocates, and business interest' (Hausman 2003:230). This lack of interest can partly be attributed to the complicated stance that feminists have historically had towards breastfeeding, as both a potential source empowerment and oppressions for women. For breastfeeding is, as Wolf has noted:

On one hand, it is a celebration of women's bodies and their ability to sustain life; it wrests control over babies from doctors, formula manufacturers, and men and gives it to women. On the other hand, breastfeeding reinforces traditional notions of women, their bodies, and their "natural" orientation towards caregiving; it keeps women tethered to their babies and creates risks for them in a market that demands total commitment from 'ideal workers' (Wolf 2013:148)

Family policies in Iceland adhere to the dual-earner/ dual-carer model and Iceland has often been presented as a model when it comes to gender equality and parental leave provisions for fathers (Arnalds, Eydal, and Gíslason 2013; Hausmann et al. 2014). Breastfeeding rates in in the Nordic countries, including Iceland are among the highest in the world and almost all mothers initiate breastfeeding. The cultural and societal expectations for women to successfully breastfeed are therefore very high as breastfeeding represents a strong moral and social norm. As breastfeeding has increasingly become a subject of moral concern, the research that has been done on breastfeeding from a socio-cultural point of view remains very much rooted in an AngloAmerican context and has mostly been conducted in countries where breastfeeding rates remain relatively low 
and the cultural context of breastfeeding similar. This is problematic on many levels and as Lee has pointed out there is 'relatively little research of the more socio-cultural kind that seeks to investigate women's experience of feeding their babies in a context where breastfeeding is strongly promoted' (Lee 2007a:1076). This paper addresses that particular knowledge gap by reporting on the experiences of Icelandic mothers who struggle with breastfeeding.

1.3 The interaction between women who struggle with breastfeeding and health care professionals can sometimes be problematic and fraught with conflict and many women tend to feel that they did not get the help they needed and even felt that their feelings and experiences were not acknowledged. It is therefore extremely valuable to examine the role of health care professionals working 'in the field' as they possess the power to define and promote the dominant scientific discourses that women have to contend with as well as provide them and their infant feeding actions with the professional stamp of approval. By focusing on how mothers report on interactions with health care professionals, this paper makes visible the identity work that mothers perform in order to be able to construct themselves as 'good' responsible mothers despite their 'failures' in breastfeeding.

1.4 The paper starts by giving a brief overview of breastfeeding as a topic of research, internationally, as well as in Iceland. A description of the methods and methodology used in this study is then given. The following three sections present the results and discussions, exploring what difficulties the mothers face when it comes to breastfeeding, how they experience the interaction with health care professionals and society. This study acknowledges the importance of looking at the ways in which women assert their own meaning and agency within their infant feeding experiences, how they deal with the constraints of scientific discourse and how the myth(s) of motherhood are lived, fought against and transformed.

\section{Breastfeeding as a topic of research}

2.1 Research on breastfeeding has mostly been conducted within the health sciences, nursing and public health where the emphasis has been on health education and getting more mothers to breastfeed (Stearns 1999). The World Health Organization (WHO) recommends exclusive breastfeeding for the first six months of life, with continued breastfeeding up to two years of age or beyond (WHO I Breastfeeding 2015) and this has become the optimal goal of policy and practice within health care systems around the world. Breastfeeding advocacy has mostly focused on the benefits of breastfeeding for infants and women but as numerous scholars have noted there has also been a shift towards a strong rhetoric of 'the natural' when it comes to infant feeding and parenting practices more generally (Badinter 2012; Crossley 2009; Hays 1998). As Wolf has pointed out when it comes to measuring the impact breastfeeding actually has, the conclusions are at best contradictory and 'for every study linking it to better health, another finds it to be irrelevant, weakly significant, or inextricably tied to other unmeasured or unmeasurable factors' (Wolf 2007:600). Nevertheless, the assumed multitude of benefits and the supposed risk reduction of breastfeeding have become 'scientific truths' that have achieved dominance world-wide and are rarely questioned or contested.

2.2 Breastfeeding advocacy has been criticized for its role in sustaining maternal guilt and studies have shown that guilt, shame and a sense of failure feature heavily in women's accounts of formula feeding their children (Kukla 2006; Lee 2007b; Taylor and Wallace 2012). This is especially evident for women who had intended on breastfeeding, but struggled to do so and had to account for their feeding decisions to others (Ellie Lee 2007b; Murphy 1999). Studies on women who struggle with breastfeeding reveal that women are often surprised by how difficult breastfeeding is and find the situation of 'failing' to breastfeed 'upsetting, anxiety provoking and damaging to their sense of self-worth' (Williams et al. 2013: 436). Scholars have also noted that this sense of inadequacy has intensified in recent years where the shift in emphasis has been from giving benefits to avoiding harm (Kukla 2006). Studies have also shown that support and information for mothers who decide to bottle-feed is insufficient (Lakshman et al. 2009).

2.3 Numerous studies demonstrate that mothers and health professionals are affected by discourses on breastfeeding and motherhood (Andrews and Knaak 2013; Larsen, Hall, and Aagaard 2008; Murphy 2003). In light of these powerful biomedical discourses on the health benefits of breastfeeding and the 'common sense' status they have acquired it is important to examine breastfeeding from a socio-cultural vantage point by looking at the lived implications of breastfeeding for women and how they construct their infant feeding experiences. For, as Blum (1999) has noted breastfeeding is a highly racialized and class dependant topic where white, middleclass values are often sustained. The discursive role attributed to breastfeeding mothers and the agency they exert should therefore be examined as a social phenomenon that is both culturally and historically specific, not natural and universal. 


\section{The Icelandic context}

Iceland is the most gender-equal society in the world according to the 2014 Gender Gap Index

(Hausmann et al. 2014) and several international media outlets have portrayed it as being a model for gender equality and feminism, with the Guardian even describing it as 'the world's most feminist country' (Bindel 2015). The parental leave system in Iceland has been internationally recognized as being progressive when it comes to fathers; where three months are exclusively earmarked to the father and cannot be transferred to the mother. Affordable quality day care for young children is also on offer and $78 \%$ of women work outside the home (Gender Equality in Iceland 2012; Statistics Iceland 2014). The prevalence of breastfeeding is traditionally very high in the Scandinavian countries where we have witnessed an upward trend towards higher breastfeeding rates and duration (Thome et al. 2006). Almost all mothers initiate breastfeeding (Larsen and Kronborg 2013) and both policy and practice are in line with the World Health Organization recommendations. Breastfeeding rates for children in Iceland born in 2004-2008 demonstrate that $98 \%$ of children were breastfed when they were one week old and $86 \%$ exclusively breastfed at that age. Breastfeeding rates in Iceland remain at a high level as $86 \%$ of three month old children were breastfed and $67 \%$ exclusively breastfed. The breastfeeding rate for children who were 6 months old was 74\% and for one year old children the rate was 27\% (The Directorate of Health 2012).

In Iceland midwives provide care before, during, and after the birth. Women attend antenatal clinics throughout their pregnancies, staffed by midwives. Their babies are delivered by midwives, with or without the assistance of doctors. Midwives have a statutory responsibility to visit and provide care for mothers and babies for the first 6-10 days after the birth (Mæoravernd 2016). The 'natural childbirth' movement has been influential in Iceland and has gained institutional approval and successfully challenged the medical hegemony. The dominant discourses on pregnancy, birth and care are very much rooted in the rhetoric of the 'natural childbirth' movement where the emphasis has been on 'the importance of treating childbirth as an important life experience and family event rather than a medical emergency' (Beckett 2005:254). Midwives are instructed to rely on their intuition and trust women's embodied knowledge whilst also relying on objective diagnostic data (Davis-Floyd and Sargent 1997) and much of this rhetoric centres on the concept of 'the natural' and essentialist understandings of motherhood. Breastfeeding is closely tied to this ethos of 'the natural' and certain (sometimes feminist) discourses have been, as Crossley has noted 'influential in promoting breastfeeding as a way of "resisting" the medicalization of childbirth and motherhood' (Crossley 2009:71). Research in Iceland on breastfeeding is limited and almost non-existent when it comes to the experiences of those who fail to breastfeed. One small study from 2013 indicates that mothers who struggled with breastfeeding experienced 'too much pressure' from health care professionals to breastfeed and those mothers who had formula fed their babies felt that they had been moralized and shamed by breastfeeding consultants (Gísladóttir and Einarsdóttir 2013). In Norway, as Andrews and Knaak have noted, the current public health emphasis is more focused on encouraging mothers to breastfeed exclusively for six months and less on encouraging mothers to breastfeed as almost all women initiate breastfeeding (Andrews and Knaak 2013) and this holds true for Iceland as well.

2.6 As I have argued elsewhere, the decision to breastfeed in an Icelandic context is not really a 'decision', per se. Mothers are simply expected to breastfeed and the assumption that all mothers would want to breastfeed (for some length of time at least) is completely taken for granted (Símonardóttir 2016). Exclusive breastfeeding is constructed as a pillar of successful bonding and attachment and absolutely paramount when it comes to promoting the close primary relationship between mother and child. Breastfeeding is constructed simultaneously as a learned skill where the mother needs to adopt from the beginning certain techniques that require training and also, as a completely natural process. It should also be noted that the emphasis placed on exclusive breastfeeding for the first six months and ideas about shared parenting are contradictory, as fathers are biologically incapable of breastfeeding. Fathers do not possess the same useful body and are discursively sidelined and constructed as valuable assistants who can and should show support for the mother-child dyad (Símonardóttir 2016).

\section{Methods}

3.1 This study represents one aspect of a larger study on motherhood in Iceland currently underway. Whilst gathering data on motherhood/mothering and the social and discursive constraints that mothers have to contend with I became aware of the importance that is placed on breastfeeding both in scientific discourse and among the general public. I also noticed the extreme pressure that Icelandic women are under to be able to exclusively breastfeed for a specific period of time. It became apparent to me that this pressure and the importance that is placed on breastfeeding is one of the biggest sites of normalization and discipline of the maternal body/mind and I felt that this was especially evident in Iceland where almost all women initiate breastfeeding and breastfeeding is constructed as the only option. In a Swedish context breastfeeding is the 'cultural norm' and synonymous with 
good mothering (Flacking et al. 2007) and I would suggest that the same holds true for Iceland. It is therefore important to look at the experiences of those who 'fail' in this 'culture of breastfeeding' as their experiences have been marginalized within dominant health care discourses and they in turn have to contend with the dominant cultural narrative that proclaims that breastfeeding is the only option.

In order to explore the experiences of Icelandic mothers who had encountered problems with breastfeeding I decided to advertise the study and ask women directly to submit their written stories/narratives to me. I introduced the study and asked women to participate on several Facebook groups for Icelandic mothers and the request was circulated widely. The daily newspaper, Fréttablaðið, even picked up the story and published an interview with me on their online website where I explained the background and aims of the study. The response exceeded all my expectations as over 90 women expressed an interest in the study and 77 women submitted their stories in October and November of 2015. Some of the respondents requested more information and were subsequently sent a list of questions that they could keep in mind when writing their stories, see Table 1.

Table 1: Questions for consideration

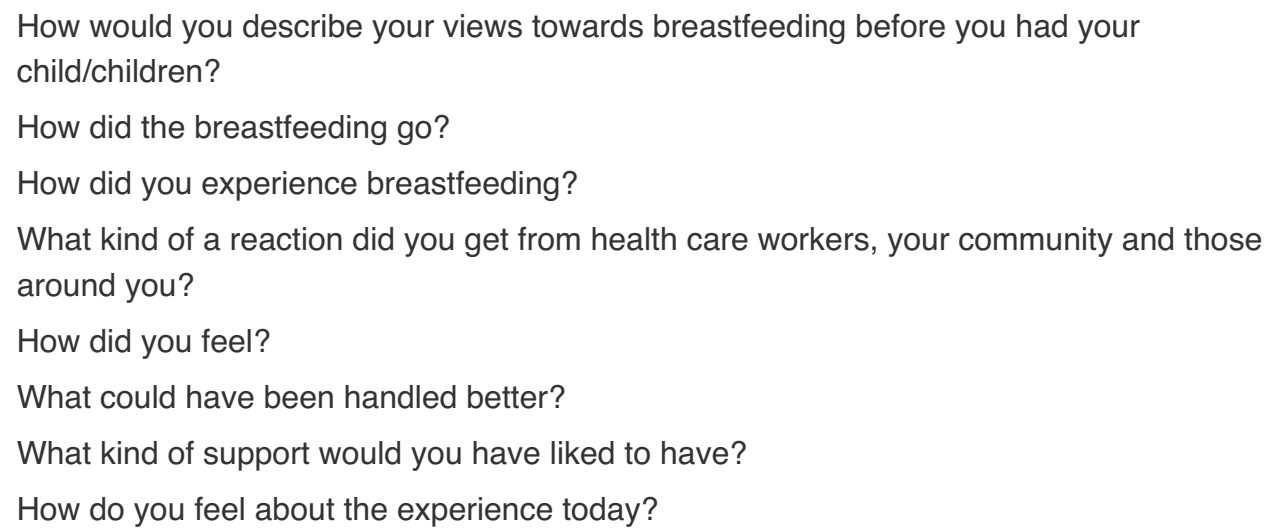

3.3 This particular study design meant that the participants could reveal as much or as little about their feelings and experiences as they wished to and they were completely in control of their own narrative. They themselves decided just how much information was given and in what way and for this particular topic, where there is a lot of stigma attached. This proved to be extremely fruitful, as the data gathered was very interesting and meaningful to the respondents, many of whom expressed their gratitude for being able to share their stories with someone who was interested in what they had to say. The stories varied in length, the shortest comprising only of rather short answers to the questions I had put together, and the longest several pages of text, altogether the data consisted of over 124 pages of text. Possible limitations of this particular study design are that the participants self-selected themselves to take part in the study and the findings should therefore not be seen as representative of all Icelandic mothers who struggle with breastfeeding. It is quite possible that the women who struggled the most or had a particularly negative experience of breastfeeding would be more likely to want to take part in the study.

3.4 Postmodern perspectives rely on the deconstruction of texts in order to reveal dominations, oppositions, contradictions and inconsistencies (Creswell 2013). I treated the stories as data and after several thorough readings of the data they were coded and thematised accordingly. I used ATLAS.ti, a qualitative data analysis program, to organize, process and identify patterns. The two major categories that followed from the analysis were the internal and external factors that affected the mothers and for the purpose of this paper I focused on the latter category. External factors that had an impact on the mother were found to be health care professionals or "the experts", family members, especially husbands and partners and society. Those categories were then analyzed further and in order to not only analyse what was being said, but also what remains 'hidden', 'natural' and 'common sense' I used discourse analysis to 'locate and analyse the mechanisms by which meaning is produced, fixed, contested, and subverted' (Howarth et al. 2005: 341). I approached the data asking what moral work was being undertaken by the participants and how they describe their experiences as well as how they construct themselves and their children. I was interested in looking at the discursive space that the participants inhabit and how (and if) they challenge dominant discourses on breastfeeding and what it means to be a good and responsible mother. All the stories that were analysed were in Icelandic and the quotes presented in this paper have consequently been translated into English by the author. 
When we examine infant feeding practices and the impact of those practices on mothers we must be mindful of the fact that disciplinary power has historically incorporated psychological theories and biomedical research findings to normalize different kinds of infant feeding practices (depending on time and place) and simultaneously created or reinforced negative discourses around other approaches. Mothers who fail to breastfeed have been the subject of a lot of research where they (and their actions) are constructed as something that needs fixing, something that is not ideal practice. The aim of this particular kind of breastfeeding research is to enhance breastfeeding promotion and policy and help educate and persuade more women to breastfeed (Lee 2007b). This was on the other hand not the goal of this study and is reflected in the study design and the idea behind it, of empowering individuals by asking them to share their stories in an environment where their experiences are often marginalized, pathologized and even silenced.

\section{What went wrong?}

4.1 The biomedical discourse that has achieved dominance within our current cultural climate considers breastfeeding to be a matter of individual choice (Ryan et al. 2010) and although all the Icelandic mothers in the study wanted to breastfeed, they all experienced severe difficulties such as damaged nipples, mastitis, yeast infections or great pain. For some, the milk supply was low or non-existent and for others the milk supply decreased over time. Some mothers were not able to establish any breastfeeding; others were able to breastfeed for a short period of time and a number of mother's encountered problems (for weeks and even months) but were able to carry on with breastfeeding despite those obstacles. For most of the mothers, trying to maintain breastfeeding meant that they were in great pain for a considerable period of time and many of them described the pain involved with giving birth as 'child's play' compared with the excruciating pain that they experienced when breastfeeding. As Eva explains; 'There was a period of time where I would have been more than happy to have someone cut off my breasts and sew me back together'. Some of the women felt that the pain they experienced was not taken seriously enough by health care professionals and this relates well to dominant ideas about pain in labour as something that women simply have to endure in order to achieve a 'natural birth'. This normalizing of women's suffering can be seen as both moralistic and prescriptive, as it assumes that women should endure extreme pain in order to prove their love and devotion to their child.

4.2 Some of the women were told by health care professionals that 'All mothers were created to be able to breastfeed' but the women were also told that their problems stemmed from having breast implants, not getting enough exercise, not feeding their babies frequently enough, not being able to put them to breast properly. Some were told they had 'impossible nipples' and others were told that their lack of milk production was the result of a 'psychological problem'. This idea that women have a 'natural ability' to breastfeed is culturally very strong but at the same time is counteracted with messages about the possible 'faults' that the women possess. They are discursively situated as both 'natural' and 'unnatural' at the same time, and in order to successfully breastfeed they have to rectify those unnatural faults often by going through quite technical processes, involving a range of breastfeeding aids such as breast pumps, artificial breasts and finger- or syringe feeding systems.

4.3 The women invested a great deal of physical and emotional energy into trying to establish breastfeeding and when they encountered problems with their milk supply/production they were encouraged to increase the number of feeds dramatically and additionally, use an electric breast pump to enhance milk production. For many of the women this meant that they spent their days and even nights either trying to breastfeed or when their babies were sleeping, expressing milk with the electric breast pump. For many of the women, this project, trying to establish breastfeeding was so extensive that they could not do, or think about anything else. For some the experience was like being under house arrest and others felt as if they were cows, tied to a stall. There was no time to rest, eat, sleep or even enjoy this new role of being a mother. In this quote Agla illustrates this experience well:

When I look back at those weeks when I was trying to breastfeed I feel bad. This was a really bad period for me, the baby and my partner. During this time I was kind of just 'plugging away' with the breastfeeding. Every hour in the day revolved around trying to feed my son. I didn't really know this child, I was just either waking him up, trying to get him to sleep, pumping or feeding him from the breast or the bottle. There was no time to look at the baby, enjoy holding him and being his mother.

4.4 When it comes to failing to achieve something that is meant to be both easy and natural the women are quick to blame themselves for that which their bodies did not produce and for some this struggle to breastfeed is totally unexpected and very difficult to come to terms with. As good mothers, they must prioritise their babies' interests ahead of their own and often sacrifice their own emotional and physical wellbeing in order to do so. Giving up breastfeeding is not constructed as a legitimate choice at this point as the women's stories clearly 
reveal. They must try everything in their power to persist with breastfeeding and in order to do so most of them consult with specialists, nurses, midwives and lactation consultants, all of which are considered breastfeeding experts within the Icelandic health care system. The women seek out the expert knowledge of those health care professionals whose authoritative status affords them the right to communicate the 'rules' of successful breastfeeding, which the women then are supposed to follow.

\section{The Experts}

5.1 As Murphy has noted 'the state's attempts to influence mothers' feeding practices operate largely through education and persuasion' (Murphy 2003:433) and when Icelandic women encounter difficulties with breastfeeding they are advised to turn to midwives, as they have a statutory responsibility to visit and provide care for mothers and babies for the first 6-10 days after the birth. Women who struggle with breastfeeding can also make appointments with lactation specialists, either working within the hospital or independently but the lactation specialist has emerged as a whole new professional sector over the past 40 years (Lee et al. 2014; Williams et al. 2013). The women in this study mainly interact with nurses, midwives and lactation specialists, as they possess the status of being breastfeeding experts, and to a lesser degree doctors; general practitioners and paediatricians. For some of the women the support and guidance they received from health care professionals was exemplary and they never felt pressured or moralized and their experiences of health care professionals were entirely positive. For most of the women, on the other hand, this was not the case. For many of the women their interactions with breastfeeding experts only added to their distress and guilt about not being able to breastfeed their babies. As Burns et al have noted 'midwifery discourses can be pivotal in shaping the woman's experiences' and midwifery care has also been predominantly breast centred rather than woman centred (Burns et al. 2012). The support that women receive for breastfeeding has also been shown to be lacking (Mclnnes and Chambers 2008; Schmied et al. 2011) and this lack of support was also evident in this study. It is nonetheless important to note that health care professionals, midwives in particular are expected to hold two sometimes conflicting positions as both providers of care and support for mothers and at the same time to promote and support breastfeeding as the optimal method of infant feeding (Leap 2009; Lomax 2013).

Scholars have noted how the 'natural birth' movement wanted to reclaim birth as a natural process from patriarchal physicians and bring control back to the individual mother who should trust in her natural abilities and forgo pharmacological and surgical interventions (Michaels 2014; Williams et al. 2013). Breastfeeding can be seen as a component of this natural birthing movement (Rooks 1997) where a 'hegemonic valorisation of the "natural" that may be just as problematic as a valorisation of the "medical"' (Williams et al. 2013) and where restrictive dualisms are reproduced. The power dynamics of this particular relationship between mother (patient) and expert are clearly hierarchical, where the latter is in a position to shame and even scold, and the former feels that she has lost her subject status and is even treated like a child;

Support was non-existent, I was alone and helpless, both with regard to the health care professionals and my family. When I decided to stop the hard work [breastfeeding] the midwife became very angry with me, it didn't matter that I had 40 litres in the freezer that would be enough for the baby for two months! She scolded me like a little child, that I was ruining the child's life on purpose (Andrea).

5.3 The language and choice of words used by many of the women indicate how the women feel themselves infantilized by health care professionals who have the power to allow or disallow and lay down the rules. Some of the women construct their experiences as almost completely passive, where they have lost all control over their actions and midwifes and other health care professionals 'make them' do and try various things to help with the breastfeeding, others admit to simply being afraid of the health care professionals. Iðunn described her feelings towards this helplessness in the following way; 'I didn't really dare do anything other than what they told me, they are the experts after all' and Magnea felt like all of the sudden she had become this kind of 'mummy figure' who the nurses and midwifes could 'poke and squeeze'. Guðrún described her experiences in the following way;

Like with the breastfeeding, I was a first time mother, I didn't know anything, I wasn't entitled to my own pain, my feelings, and I didn't matter at all, everyone knew better than I did.

5.4 Many of the women described how the health care professionals had expressed very negative views towards formula and others had a hard time getting information on formula feeding from health care professionals, who wouldn't comment on practical information, like quantity, the number of feeds and so on. Kristín felt that 'there was a lot of emphasis placed on everything I did not do enough of or did incorrectly'. Many of the mothers associate health care professionals with being judged and having to explain and justify their infant feeding practices. For Fanney this proved difficult: 
Taking [daughter] to the antenatal clinic was always hard, I was young and not breastfeeding. I always got the same questions, Why didn't you try harder? Why this and why that? Those questions were always very uncomfortable.

Beckett has noted how there is a real tendency to treat midwifery as synonymous with feminism and 'to overlook possible conflicts between midwives and birthing women' (Beckett 2005:259) and for Auður this conflict was the result of her wanting to quit breastfeeding, after 6 months of difficulties and telling her midwife, who then responded by saying 'that she didn't feel it was timely, as he was "only" six months old'. The midwife is in this scenario able to allow or disallow Auður's request, who subsequently 'felt like a failure for quitting [breastfeeding] now'. This interaction between mother and midwife clearly demonstrates just how powerful the midwife is when it comes to the mother's identity and the discursive space she inhabits. If the midwife had responded in a more positive way, Auður would perhaps have been proud of the fact that she persisted with breastfeeding for six months and had been able to construct her breastfeeding experience as an achievement and from a place of strength. Some of the women feel that the actions or inactions of health care professionals have put their babies at risk and for others the advice offered by health care professionals was 'useless or directly harmful'. This usually has to do with the reluctance of the breastfeeding experts to allow/advise the mothers to supplement with formula when the mothers are not producing enough milk or experiencing other kinds of difficulties. Agla's baby did not reach its birthweight until it was 6 weeks old and in her opinion 'this should have been ample reason for the health care professional to react'. Sylvía had a similar experience and asserted in her story that according to the advice she received from health care professionals 'she should rather suffer and starve her baby than feed him something else [other than breastmilk]'.

\section{Getting the green light}

6.1 Most of the women experience immense pressure from health care professionals to keep trying to breastfeed, even when it is clearly not going well. They are advised to try everything possible to avoid supplementing with formula and endure a great deal of emotional and physical pain in order to persist with breastfeeding. Often the mothers feel that they themselves are not in a position to make decisions about introducing formula or to stop breastfeeding, as that decision should be left to the experts and they themselves often feel quite powerless. Some of the women refer to this, being 'allowed' to stop breastfeeding or supplementing with formula, as being given the green light from the breastfeeding experts, and often it is this green light that they so desperately want and need. This realization, that they were so desperate for someone with an expert status to give them permission to stop this often excruciatingly painful and emotionally and physically exhausting task of trying to breastfeed, has perhaps come to them later, when they have had time to think and reflect on their situation. Guðrún is adamant about what she needed at that time in her life:

I couldn't breastfeed, then the baby will be bottle fed, but in all the doctors' visits, all the telephone consultations, email communications and et cetera, no one told me what I needed to hear. Just quit breastfeeding her, the formula is just as good and it will all be OK, you are doing the right thing for both of you.

6.2 Friðrika is one of the many women who wanted to stop breastfeeding but was unable to make that decision for herself, she says: 'Under the surface I wanted someone to take the control from me and tell me that I needed to stop this... I felt that everyone was judging me'. Auður still feels angry about her treatment and says; 'what I have a problem with is how long I was made to suffer... Why did they push me into carrying on with breastfeeding after all that I had been through?' Linda had a similar experience and looking back she wished that someone had said to her 'Hey you know it's OK for the baby to just get a bottle! And it would have mattered the most coming from a health care professional'.

6.3 It is extremely important to the mothers to be acknowledged by health care professionals as good mothers who did the best they could for their babies and as Elísa says: 'I would have liked to hear that no matter what I did, I would be a good mother. I did not want to be despised just for the fact that I fed him from a bottle'. As Faircloth has pointed out, 'among all the elements of mothering, infant feeding has been one that is most conspicuously moralized' (Faircloth 2009, p.15) and this is also evident in the women's narratives as they negotiate the two seemingly conflicting identities of 'failing at breastfeeding' at one hand, and being considered a 'good mother' on the other. Should a mother exercise her own agency and decide for herself that the best thing for her would be to give up on trying to breastfeed, she runs the risk of being constructed as the villain, the selfish mother who didn't want to inconvenience herself for the sake of her child. The biggest sin according to this cultural script of good mothering is not trying hard enough and giving up without a fight. The women want an outsider, especially a health care professional to tell them that they have done enough and that they have passed the test, but for some of the women no one ever does. 
When the breastfeeding experts that women mostly interact with, nurses and midwives, fail to provide women with the 'green light' that they so desperately want, they are sometimes presented with a 'way out' from their husbands and partners. As Crossley has rightfully noted there seems to be a real absence of fathers in the literature on breastfeeding and 'almost no recognition at all of the fact that women struggle with breastfeeding in the context of relationships with their partners' (Crossley 2009:75). The father is often in a prime position to witnesses the effects that breastfeeding (or trying to breastfeed) has had on the mother. His unique position as both an insider, a parent to the child and a participant (to some degree) in the quest to establish breastfeeding, and as an outsiders, as he is not subjected to the same disciplinary practices and scrutiny that mothers encounter, often enables him to reject and call in to question the advice and recommendations of the breastfeeding experts. For Álfheiður this meant that her partner was more open to trying formula then she was:

My partner supported me the whole time, he communicated with the health care clinic, found information, sought out and called for help and kept the option of using formula open, but somehow I got stuck in trying to make it [breastfeeding] work.

6.5 When Rebekka was home from the hospital and no longer 'under pressure' she switched to formula feeding for her twins because of the support she felt from her husband and sister and other women share her experience. The women sometimes describe their partners having a more rational view of the situation, and when they themselves are 'caught up in the storm', trying their best to follow the rules, their partners are the only ones who can truly see the damage that is being done. For Arndís, this meant that her partner asked her directly to stop trying to breastfeed as 'he clearly saw what it was doing to my mental side' and Linda's partner asked her if they 'really had to do all this'. These findings correspond with the findings of Crossley (2009) who experienced the same kind of relief when her partner insisted on giving their baby a bottle and 'give me the opportunity to get my body and life back into some kind of order' (Crossley 2009:84). As Kukla notes, 'most mainstream and authoritative breastfeeding sources insist that breastfeeding poses no deep difficulties or risks for women' (Kukla 2006:168) and for the fathers to challenge this assumption directly to their partners sometimes meant that the mothers were able to go against the breastfeeding experts and stop trying.

\section{Society}

7.1 Dominant discourses and 'scientific truths' on infant feeding and good mothering do not exist in a vacuum, solely confined to hospitals or health care clinics. The concept of 'bonding through breastfeeding' was for example first championed by the 'natural childbirth' movement and later incorporated by the traditional medical community and has now entered both the professional and popular discourse (Crouch and Manderson 1995; Kukla 2008). The long list of the assumed benefits of breastfeeding has also become common knowledge (Murphy 1999) and some of the women found their breastfeeding (or lack thereof) was an acceptable topic of conversation, even from strangers. Rós experienced this kind of public shaming from a stranger and describes the experience in this way:

\footnotetext{
There was this one time when I went to a café with my family. My boy was hungry and I asked the girl who was working there if she could heat up some milk for the bottle for me. There was a small line in the café and I notice that the man standing behind me seemed outraged 'What, have you just taken the breast away from the child?!?' [he says]. This cut me up inside even though I didn't have the nerve to say anything to him. Finally there was someone who didn't know my history and therefore dared to say what he thought about the formula.
}

7.2 For Rós, this man standing in line at the café is daring to say what others think, but cannot say, that the child is being cheated out of something that is rightfully his, his mother's milk and consequently that she has failed her child. As Stearns has pointed out the breastfeeding body, like the pregnant body, is in many ways a public good 'and thus open for public comment' (Stearns 1999:308) and this open invitation to comment can prove very painful and demoralizing for mothers who are struggling with breastfeeding. For Guðbjört the criticism that was directed at her implied 'that I just hadn't been hard working enough' and for Dögg the comments and criticisms had a very negative affect on her:

I would have liked if people had shown me support and sometimes it was as if people didn't realise that I had feelings. I cried myself to sleep countless times during that time because of how people treated me.

7.3 It has been noted how pregnant women are kept under surveillance and expected to act in ways that are deemed responsible to the baby they carry and to themselves (Locke and Horton-Salway 2010) and this holds true for breastfeeding mothers as well, who have to account for their feeding choices to friends, family members and even strangers. Soffía was mindful of that and 'didn't go around advertising or telling everyone that [she] wasn't breastfeeding her [child]'. In Porbjörg's experience everyone around her seemed to have an opinion and 
felt the need to advise her:

I just felt like a complete 'looser' for not producing any milk. What is it when people come to visit to see a mother with her new-born and the first question is 'and the breastfeeding is going well, right?' I had started to hide myself in the bedroom to give her the bottle because people constantly had to give me advice.

7.4 This kind of interference and unsolicited advice and attention means that the women start to expect being under surveillance, preparing for the hostile gaze of others, with a list of excuses ready at the tip of their tongues. Erla explains this feeling of being prepared when she says 'No one has given me a hostile look or told me that this isn't good for my children but still I keep on making excuses'. The surveillance is now sustained on an interpersonal level where the mothers are monitored not only by others but also by themselves.

\section{Judging other mothers}

7.5 Many of the women felt that this surveillance was mostly administered by other women and as Kukla has noted breastfeeding operates as a 'signal issue' which assigns women into different parenting camps (Kukla 2006). This idea of competition and comparing and ranking among mothers presents itself in various circumstances for the women, for example among friends or family or in the 'mummy groups' that the women attend. For Sandra, in her previous experience of breastfeeding she felt that it was 'very important to show others that I was competent, that I could follow the rules' and 'who was watching and judging? Well, other women'. Sandra had come to realise that other mothers were taking part in what Foucault has called strategies of normalization and exclusion, which may present themselves as ranking, comparing, classifying and dividing (Foucault 1977).

7.6 The culturally specific understandings of what it means to be a good mother can create an environment where mothers engage in competitive behaviour and for some of the women, being surrounded by other women who had breastfed their babies without difficulties made them experience a lot of pressure to be able to do so as well. This competitive atmosphere can be especially damaging to those women who formula fed as Pórunn explains: 'I went to a "mummy group" and there were so many stares when I picked up the bottle that I hid in the bedroom to feed him'. Others shared this experience of hiding the use of formula and this corresponds to the findings of Lee and Furedi (2005) in their study on mothers' in the UK using formula; that women whose breastfeeding attempts failed wanted to isolate themselves from other mothers. Other mothers who are able to breastfeed without difficulties are sometimes seen as being smug and condescending and Pórhalla feels that 'some mothers, who have breastfed their children for a long time, boast a bit about it'. As Bartky has noted, 'discipline can provide the individual upon whom it is imposed with a sense of mastery as well as a secure sense of identity' (Bartky 2002:39) and it is through this secure sense of identity and having successfully 'followed the rules' that women who have been able to breastfeed their children can construct themselves as 'better' and more responsible mothers. Breastfeeding does in this way become a 'measure of motherhood' and some women 'consciously or unconsciously judge other mothers accordingly' (Lee and Furedi 2005:61), primarily if they are perceived as not having tried hard enough (Andrews and Knaak 2013). Without a thorough examination of the structural underpinnings of breastfeeding it becomes almost impossible for women to understand their 'failures' in breastfeeding as anything other than a personal shortcoming, making it equally difficult for other mothers to sympathise or fully understand their experiences without having struggled with breastfeeding themselves.

\section{Conclusion}

8.1 Bartky has noted how women are in fact 'governed through their freedom, and not by coercion or force' (Bartky 2002:39) and it is important to keep in mind that it is through this lens of 'governing through freedom' that the structural foundations of breastfeeding-work should be viewed. Icelandic mothers are indeed not forced to breastfeed, nor are they coerced into trying absolutely everything in order to succeed with breastfeeding. They choose to breastfeed and it is their choice to exhaust every possible avenue in trying to make breastfeeding work. The notion of freedom and choice does however become debatable when we consider the culture that they inhabit, where almost all women initiate breastfeeding and the notion of 'giving up' on breastfeeding means that you have failed your child and your identity as a 'good mother' is challenged. 
stop trying. Fathers are mostly absent from the literature on breastfeeding but as this study reveals, their role can be pivotal. Fathers do not have to contend with the same normalizing discourses as mothers do, and their identity as fathers is not as closely tied up with the rhetoric of 'good mothering' or scientific truths. They can present women with a 'way out', simply by openly questioning the rules of infant feeding and relieving the women of some of the burden of responsibility.

The high breastfeeding rates in Iceland as well as the shared understanding of breastfeeding as 'the right thing to do' has implications for those women whose bodies 'fail' them. Their non-breastfeeding bodies are open for public comment and questioning and they are often expected to account for their infant feeding practices to friends, family and even strangers. This surveillance of mothers is sustained on an interpersonal level where mothers are constantly preparing for the hostile gaze of others. They feel that their mothering capabilities and devotion to their child are being ranked and compared, especially by other mothers who judge them both consciously and unconsciously.

The women's narratives clearly demonstrate a need for a cultural change in postnatal care. The 'natural childbirth' movement has been successful in changing the discourse on pregnancy, birth and breastfeeding by incorporating feminist aspirations of female autonomy and a reclaiming of the female body from medicalization. The discursive shift from the 'medical' to the 'natural' has been successfully implemented without any recognition of the fact that the 'natural' is also a cultural category, and has no intrinsic meaning. The unequal power relations between patient (female) and physician (male) that were once so strongly criticized have not been discarded, but simply re-imagined and reproduced within current health care systems. By proclaiming that all women have a 'natural' ability to breastfeed, for as long as they wish, the experiences of a large number of women are marginalized and pathologized and essentialist understandings of women as a homogenous group are sustained. This study, on Icelandic mothers who struggle with breastfeeding is an attempt to let the voices of those who have been silenced by dominant health care discourses be heard and to shed light on the experiences of women struggling to breastfeed in a culture that proclaims, not only that breast is best, but simply the only option.

\section{Acknowledgements}

I would like to thank the reviewers of the paper for their valuable and thoughtful comments and suggestions. I am grateful to my supervisor Dr. Ingólfur V. Gíslason for his guidance and to the members of my doctoral committee Dr. Annadís Rúdólfsdóttir, Dr. Ellie Lee and Dr. Helga Gottfreðsdóttir for their assistance.

The doctoral research project from which this paper is drawn is funded by the Icelandic Research fund (141617052) and The Governmental Gender Research Fund.

\section{References}

ANDREWS, T. and Knaak, S. (2013) Medicalized Mothering: Experiences with Breastfeeding in Canada and Norway. The Sociological Review61 (1): p. 88-110. doi:10.1111/1467-954X.12006.

ARNALDS, Á.A., Eydal, G.B. and Gíslason, I.V. (2013) Equal Rights to Paid Parental Leave and Caring Fathers the Case of Iceland. Icelandic Review of Politics and Administration9 (2): p. 323-44.

BADINTER, E. (2012) The Conflict: How Modern Motherhood Undermines the Status of Women New York: Metropolitan Books.

BARTKY, S. (2002) Foucault, Femininity and the Modernisation of Patriarchal Power.Social and Political Philosophy: Classical Western Texts in Feminist and Multicultural Perspectives, 3 edition. Belmont, CA: Wadsworth Publishing.

BECKETT, K. (2005) Choosing Cesarean Feminism and the Politics of Childbirth in the United States.Feminist Theory 6 (3): p. 251-75. doi:10.1177/1464700105057363.

BINDEL, J. (2015) "Iceland: The World's Most Feminist Country." The Guardian. Accessed February 9. http://www.theguardian.com/lifeandstyle/2010/mar/25/iceland-most-feminist-country. 
BLUM, L.M. (1999) At the Breast: Ideologies of Breastfeeding and Motherhood in the Contemporary United States. Beacon Press.

BURNS, E., Schmied, V., Fenwick, F. and Sheehan, A. (2012) Liquid Gold from the Milk Bar: Constructions of Breastmilk and Breastfeeding Women in the Language and Practices of Midwives. Social Science \& Medicine 75 (10): p. 1737-45. doi:10.1016/j.socscimed.2012.07.035.

CRESWELL, J.W. (2013) Qualitative Inquiry and Research Design: Choosing Among Five Approaches. Third Edition. SAGE Publications.

CROSSLEY, M.L. (2009) Breastfeeding as a Moral Imperative: An Autoethnographic Study.Feminism \& Psychology 19 (1): p. 71-87. doi:10.1177/0959353508098620.

CROUCH, M. and Manderson, L. (1995) The Social Life of Bonding Theory.Social Science \& Medicine 41 (6): p. 837-44. doi:10.1016/0277-9536(94)00401-E.

DAVIS-FLOYD, R.E. and Sargent, C.F. (1997) Childbirth and Authoritative Knowledge: Cross-Cultural Perspectives. University of California Press.

FAIRCLOTH, C. (2009) Mothering as Identity-Work: Long-Term Breastfeeding and Intensive Motherhood. Anthropology News 50 (2): p. 15-17. doi:10.1111/j.1556-3502.2009.50215.x.

FLACKING, R., Ewald, U. and Starrin, B. (2007) 'I Wanted to Do a Good Job': Experiences of 'becoming a Mother' and Breastfeeding in Mothers of Very Preterm Infants after Discharge from a Neonatal Unit. Social Science \& Medicine 64 (12): p. 2405-16. doi:10.1016/j.socscimed.2007.03.008.

FOUCAULT, M. (1977) Discipline and Punish: The Birth of the Prison. Vintage Books.

GENDER EQUALITY IN ICELAND: Information on Gender Equality Issues in Iceland. (2012) Centre for Gender Equality Iceland. http://eng.fjarmalaraduneyti.is/media/Gender_Equality_in_Iceland_012012.pdf.

GíSLADóTTIR, E.Ö. and Einarsdóttir, J. (2013) Mother's Views on Breastfeeding Counselling in Iceland: Qualitative Study. Ljósmæðrabladid 1 (91): p. 6-12.

HAUSMAN, B.L. (2003) Mother's Milk: Breastfeeding Controversies in American Culture. 1 edition. New York: Routledge.

HAUSMANN, R., Tyson, L.D., Bekhouche, Y. and Zahidi, S. (2014) The Global Gender Gap Report 2014. http://reports. weforum.org/global-gender-gap-report-2014/economies/\#economy=ISL.

HAYS, S. (1998) The Cultural Contradictions of Motherhood. Yale University Press.

HOWARTH, D. And Torfing, J. eds. (2005) Applying Discourse Theory: The Method of Articulation.Discourse Theory in European Politics. Houndmills, Basingstoke, Hampshire: New York: Palgrave Macmillan.

KUKLA, R. (2006) Ethics and Ideology in Breastfeeding Advocacy Campaigns. Hypatia 21 (1): p. 157-80. doi:10.1111/j.1527-2001.2006.tb00970.x.

KUKLA, R. (2008) Measuring Mothering. IJFAB: International Journal of Feminist Approaches to Bioethics1 (1): p. $67-90$.

LAKSHMAN, R., Ogilvie, D. and Ong, K.K. (2009) Mothers' Experiences of Bottle-Feeding: A Systematic Review of Qualitative and Quantitative Studies. Archives of Disease in Childhood94 (8): p. 596-601. doi:10.1136/adc.2008.151910.

LARSEN, J.S., Hall, E.O.C. and Aagaard, H. (2008) Shattered Expectations: When Mothers' Confidence in Breastfeeding Is Undermined - a Metasynthesis. Scandinavian Journal of Caring Sciences22 (4): p. 653-61. doi:10.1111/j.1471-6712.2007.00572.x.

LARSEN, J.S. and Kronborg, H. (2013) When Breastfeeding Is Unsuccessful - Mothers' Experiences after Giving up Breastfeeding. Scandinavian Journal of Caring Sciences27 (4): p. 848-56. doi:10.1111/j.14716712.2012.01091.x.

LEAP, N. (2009) Woman-Centred or Women-Centred Care: Does It Matter? British Journal of Midwifery 17 (1): p. 12-16. doi:10.12968/bjom.2009.17.1.37646. 
LEE, E. (2007a) Health, Morality, and Infant Feeding: British Mothers' Experiences of Formula Milk Use in the Early Weeks. Sociology of Health \& IIIness 29 (7): p. 1075-90. doi:10.1111/j.1467-9566.2007.01020.x.

LEE, E. (2007b) Infant Feeding in Risk Society.Health, Risk \& Society9 (3): p. 295-309. doi:10.1080/13698570701488910.

LEE, E., Bristow, J., Faircloth, C. and Macvarish, J. (2014) Parenting Culture Studies. 2014 edition. Houndmills, Basingstoke, Hampshire; New York: Palgrave Macmillan.

LEE, E. and Furedi, F. (2005) Mothers' Experience Of, and Attitudes To, the Use of Infant Formula for Feeding Babies - Kent Academic Repository. https://kar.kent.ac.uk/25249/.

LOCKE, A. and Horton-Salway, M. (2010) 'Golden Age' versus 'Bad Old Days' A Discursive Examination of Advice Giving in Antenatal Classes. Journal of Health Psychology15 (8): p. 1214-24. doi:10.1177/1359105310364439.

LOMAX, H. (2013) Troubled Talk and Talk about Troubles: Moral Cultures of Infant Feeding in Professional, Policy and Parenting Discourses. In Family Troubles? Exploring Changes and Challenges in the Family Lives of Children and Young People, edited by Jane Ribbens McCarthy, Carol-Ann Hooper, and Val Gillies, p. 97-106. Bristol: Policy Press. http://oro.open.ac.uk/31064/.

MCINNES, R.J. and Chambers, J.A. (2008) Supporting Breastfeeding Mothers: Qualitative Synthesis. Journal of Advanced Nursing 62 (4): p. 407-27. doi:10.1111/j.1365-2648.2008.04618.x.

MICHAELS, P.A. (2014) Lamaze: An International History. OUP USA.

MURPHY, E. (1999) 'Breast Is Best': Infant Feeding Decisions and Maternal Deviance.Sociology of Health \& IIIness 21 (2): p. 187-208. doi:10.1111/1467-9566.00149.

MURPHY, E. (2003) Expertise and Forms of Knowledge in the Government of Families.The Sociological Review 51 (4): p. 433-62. doi:10.1111/j.1467-954X.2003.00430.x.

ROOKS, J. (1997) Midwifery and Childbirth in America. Temple University Press.

RYAN, K., Bissell, P. and Alexander, J. (2010) Moral Work in Women's Narratives of Breastfeeding.Social Science \& Medicine 70 (6): p. 951-58. doi:10.1016/j.socscimed.2009.11.023.

SCHMIED, V., Beake, S., Sheehan, A., McCourt, C. and Dykes, F. (2011) Women's Perceptions and Experiences of Breastfeeding Support: A Metasynthesis. Birth (Berkeley, Calif.) 38 (1): p. 49-60. doi:10.1111/j.1523-536X.2010.00446.x.

SÍMONARDÓTTIR, S. (2016) Constructing the Attached Mother in the 'world's Most Feminist Country.'Women's Studies International Forum 56 (May): p. 103-12. doi:10.1016/j.wsif.2016.02.015.

STATISTICS ICELAND. (2014) http://www.statice.is/.

STEARNS, C.A. (1999) Breastfeeding and the Good Maternal Body. Gender \& Society 13 (3): p. 308-25. doi:10.1177/089124399013003003.

TAYLOR, E.N. and Wallace, L.E. (2012) For Shame: Feminism, Breastfeeding Advocacy, and Maternal Guilt. Hypatia 27 (1): p. 76-98. doi:10.1111/j.1527-2001.2011.01238.x.

THE DIRECTORATE OF HEALTH. (2012) brjostagjof_og_naering2004_2008_lokaskjal brjostagjof_og_naering_2004-2008_juni.2012.pdf. June. http://www.landlaeknir.is/servlet/file/store93/item16573/brjostagjof_og_naering_20042008_juni.2012.pdf.

THOME, M., Alder, E.M and Ramel, A. (2006) A Population-Based Study of Exclusive Breastfeeding in Icelandic Women: Is There a Relationship with Depressive Symptoms and Parenting Stress? International Journal of Nursing Studies 43 (1): p. 11-20. doi:10.1016/j.ijnurstu.2004.10.009.

WHO I BREASTFEEDING. (2015) WHO. Accessed September 3. http://www.who.int/topics/breastfeeding/en/.

WILLIAMS, K., Kurz, T., Summers, M. and Crabb, S. (2013) Discursive Constructions of Infant Feeding: The 
Dilemma of Mothers' 'guilt.' Feminism \& Psychology23 (3): p. 339-58. doi:10.1177/0959353512444426.

WOLF, J.B. (2007) Is Breast Really Best? Risk and Total Motherhood in the National Breastfeeding Awareness Campaign. Journal of Health Politics, Policy and Law32 (4): p. 595-636. doi:10.1215/03616878-2007018.

WOLF, J.B. (2013) Is Breast Best?: Taking on the Breastfeeding Experts and the New High Stakes of Motherhood. Biopolitics. NYU Press. 